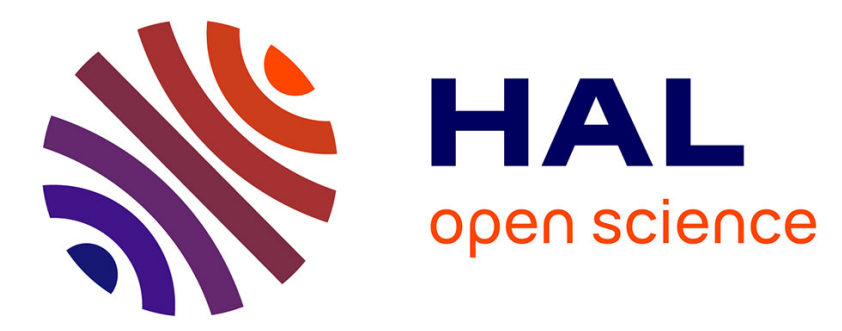

\title{
La place des inondations dans la fabrique des paysages fluviaux urbains. Le cas de la Garonne à Toulouse (du XVIIe siècle à aujourd'hui)
}

\author{
Jean-Marc Antoine, Philippe Valette
}

\section{- To cite this version:}

Jean-Marc Antoine, Philippe Valette. La place des inondations dans la fabrique des paysages fluviaux urbains. Le cas de la Garonne à Toulouse (du XVIIe siècle à aujourd'hui). Sud-Ouest Européen, 2017, Regards croisés sur les fleuves Èbre et Garonne, 44, pp.25-39. 10.4000/soe.3121 . hal-02545904

\section{HAL Id: hal-02545904 \\ https://hal.science/hal-02545904}

Submitted on 17 Apr 2020

HAL is a multi-disciplinary open access archive for the deposit and dissemination of scientific research documents, whether they are published or not. The documents may come from teaching and research institutions in France or abroad, or from public or private research centers.
L'archive ouverte pluridisciplinaire HAL, est destinée au dépôt et à la diffusion de documents scientifiques de niveau recherche, publiés ou non, émanant des établissements d'enseignement et de recherche français ou étrangers, des laboratoires publics ou privés. 


\section{La place des inondations dans la fabrique des paysages fluviaux urbains. Le cas de la Garonne à Toulouse ( $\mathrm{du}$ XVII ${ }^{\mathrm{e}}$ siècle à aujourd'hui)}

The role of floods in urban's fluvial landscape generation. The case of Garonne river in Toulouse (since the 18th century)

El papel de las inundaciones en la construcción de los paisajes fluviales urbanos. el caso del río Garona en Tolosa (desde el siglo XVII hasta la actualidad)

\section{(2) OpenEdition}

1 Journals

Édition électronique

URL : http://journals.openedition.org/soe/3121

DOI : $10.4000 /$ soe. 3121

ISSN : 2273-0257

Éditeur

Presses universitaires du Midi

Édition imprimée

Date de publication : 1 décembre 2017

Pagination : 25-39

ISBN : 978-2-8107-0549-8

ISSN : 1276-4930

Référence électronique

Jean-Marc Antoine et Philippe Valette, «La place des inondations dans la fabrique des paysages fluviaux urbains. Le cas de la Garonne à Toulouse (du XVII e siècle à aujourd'hui) », Sud-Ouest européen [En ligne], 44 | 2017, mis en ligne le 17 juillet 2018, consulté le 09 juillet 2019. URL : http:// journals.openedition.org/soe/3121; DOI : 10.4000/soe.3121

\section{(c) (†) $\odot$}

Sud-Ouest européen - Revue géographique des Pyrénées et du Sud-Ouest est mis à disposition selon les termes de la licence Creative Commons Attribution - Pas d'Utilisation Commerciale - Pas de Modification 4.0 International. 


\title{
LA PLACE DES INONDATIONS DANS LA FABRIQUE DES PAYSAGES FLUVIAUX URBAINS. LE CAS DE LA GARONNE À TOULOUSE (DU XVII ${ }^{\mathrm{e}}$ SIÈCLE À AUJOURD'HUI)
}

\author{
Jean-Marc Antoine ${ }^{1}$, Philippe Valette ${ }^{2}$
}

RÉSUMÉ - Les relations entre un cours d'eau et une ville s'expriment à travers l'ambivalence ressource-contrainte. À Toulouse, si l'eau de la Garonne est considérée comme une ressource à la base d'activités diverses (navigation, moulins...), elle est aussi une contrainte contre laquelle la société riveraine a lutté au cours du temps. Les inondations du fleuve ont participé à la fabrique des paysages fluviaux urbains, de l'implantation sur le site toulousain antique jusqu'à l'explosion urbaine postannées 1950. Si pendant de nombreuses années, les paysages urbains toulousains sont marqués par la protection contre l'aléa inondation, ils deviennent aujourd'hui le support d'activités ludiques et récréatives, à l'instar des grandes métropoles européennes. Ce vaste mouvement se traduit par une perception riveraine qui considère la Garonne à Toulouse comme une aménité environnementale et paysagère.

PAYSAGES FLUVIAUX - INONDATIONS - ENDIGUEMENT - PERCEPTION GARONNE - TOULOUSE
ABSTRACT - THE ROLE OF FLOODS IN URBAN'S FLUVIAL LANDSCAPE GENERATION. THE CASE OF GARONNE RIVER IN TOULOUSE (SINCE THE 18TH CENTURY). The relations between rivers and city are expressed through the resource-constraint ambivalence. In Toulouse, if the water of the Garonne is considered as a resource at the base of various activities (navigation, mills...), it is especially a constraint against which the waterfront society has struggled over time. The place of the floods of the river is at the origin of the urban fluvial landscapes, of the setting up on the ancient site Toulouse until the urban explosion post-1950s. If for many years, the urban landscapes of Toulouse are marked by protection against flood hazard; today they become the backdrop for fun activities, like the big European cities. This vast movement is reflected in a riverfront perception that considers the Garonne in Toulouse as an environmental and landscape amenity.

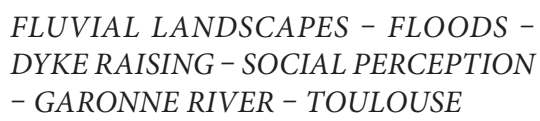

RESUMEN - EL PAPEL DE LAS INUNDACIONES EN LA CONSTRUCCIÓN DE LOS PAISAJES FLUVIALES URBANOS. EL CASO DEL RÍO GARONA EN Tolosa (DESDE EL SIGLO XVII haSTA LA ACTUALIDAD). Las relaciones entre río y ciudad se expresan a través de la ambivalencia de recursos-restricciones. En Tolosa, a la vez que el agua del Garona se aprecia como un recurso en la base de diversas actividades (navegación, molinos...), es especialmente considerada una restricción contra la cual la sociedad ha luchado a lo largo del tiempo. Las inundaciones del río están en el origen de la construcción de los paisajes fluviales urbanos, desde la instalación en el sitio antiguo de Tolosa hasta la explosión urbana posterior a los años 1950. Mientras durante muchos años los paisajes urbanos de Tolosa estuvieron marcados por la protección contra el riesgo de inundación, hoy se convierten en el telón de fondo de actividades lúdicas y recreativas, como en otras grandes ciudades europeas. Este vasto movimiento se traduce en una percepción de los ribereños que considera el Garona en Tolosa como un valor ambiental y paisajístico. PAISAJE FLUVIAL - INUNDACIONES -
DIQUESDECONTENCIÓN - PERCEPCIÓN
HUMANA - RÍO GARONA - TOLOSA

\footnotetext{
${ }^{1}$ Université Toulouse - Jean Jaurès, département de Géographie, laboratoire GEODE-UMR-5602-CNRS, antoine@univ-tlse2.fr

${ }^{2}$ Université Toulouse - Jean Jaurès, département de Géographie, laboratoire GEODE-UMR-5602-CNRS, philippe.valette@univ-tlse2.fr
} 
$\ll \mathrm{R}_{\mathrm{n}}^{\mathrm{a}}$ aides, bétonnées, géométriques, les villes modernes ont aplati les subtilités topographiques, géologiques, hydrographiques sur lesquelles elles s'imposent » (Piel, 2014). Depuis leurs genèses, les villes situées à proximité des cours d'eau ont appris à construire avec l'eau, à la fois en se protégeant contre les crues et en valorisant les ressources. Cette ambiguïté liée à la présence de l'eau des fleuves en ville est à l'origine de la fabrique de paysages fluviaux urbains spécifiques.

Les paysages sont des objets d'interface par excellence, résultat d'une coconstruction par les processus naturels et les processus sociaux qui animent les socio-écosystèmes, de processus actuels et d'héritages, de réalités matérielles et de représentations idéelles, ainsi que l'ont défini G. Bertrand (1978, p. 249) - « Le plus simple et le plus banal des paysages est à la fois social et naturel, subjectif et objectif, spatial et temporel, production matérielle et culturelle, réel et symbolique, etc. [...] Le paysage est un système qui chevauche le naturel et le social. [...] Il est une interprétation sociale de la nature. » -, ou, de façon plus concise la convention européenne du paysage de Florence (conseil de l'Europe, 2000) : « Le paysage désigne une partie de territoire telle que perçue par les populations, dont le caractère résulte de l'action de facteurs naturels et/ou humains et de leurs interrelations ${ }^{1} »$.

Cette nature hybride marque sans doute plus que tout autre les paysages fluviaux urbains, situés à l'interface de l'eau et de la terre ferme, de la «nature » et de la ville. Néanmoins, il est un facteur qui les conditionne tout particulièrement : les inondations. Elles ont des impacts directs sur le paysage à travers des effets sur la géométrie du lit, sur les formes fluviales et les types de berges. Les inondations ont, également, des impacts indirects à travers l'édification d'ouvrages de protection, les types d'occupation des berges, les usages du fleuve et une perception-identification du paysage fluvial par les populations riveraines et/ou usagères. D'autre part, en fonction du caractère de l'aléa, les réponses des sociétés riveraines peuvent varier au cours du temps. Cependant, l'objectif est souvent de rendre la ville étanche à l'eau d'inondation.

Cet article se propose d'explorer la façon dont les inondations, directement ou indirectement, ont progressivement modelé les paysages fluviaux garonnais à Toulouse

\footnotetext{
1 https://rm.coe.int/

CoERMPublicCommonSearchServices/

DisplayDCTMContent? documentId=090000168008062a
}

au cours de l'Histoire, et comment elles influencent aujourd'hui encore ou pas la perception de ces paysages par les toulousains.

\section{I - Le fleuve à l'œuvre}

Même en milieu urbain où l'artificialisation est la règle, le paysage fluvial est initialement l'œuvre du fleuve luimême ; et ce, à plusieurs échelles temporo-spatiales : du lit mineur aux différentes terrasses alluviales, des actions quaternaires aux retouches accessoires et plus ou moins éphémères qu'apportent les crues et les inondations...

\section{Toulouse et la Garonne}

Il n'est pas un auteur ayant écrit sur la Garonne qui ne se soit attardé sur le tracé singulier du fleuve à Toulouse : la ville s'est en effet développée à $145 \mathrm{~m}$ d'altitude au creux de la grande courbure qui infléchit brusquement le cours du fleuve vers le nord-ouest, alors qu'il suivait une direction sud-ouest/nord-est depuis sa sortie des Pyrénées. C'est qu'au cours du Quaternaire, la Garonne a été repoussée toujours plus à l'est sous l'action conjuguée du dégagement des terrasses alluviales en rive gauche par l'incision du fleuve dans ses alluvions, et de l'obstacle constitué à l'ouest par le cône torrentiel du Lannemezan, mis en place au Tertiaire puis basculé vers l'est au Quaternaire ancien.

L'implantation et le développement de la ville en ce lieu précis ont été guidés par des considérations classiques. La première correspond à la présence d'un gué ménagé à la faveur d'un banc de molasse (le Bazacle) et d'un palier alluvial insubmersible en rive droite au pied de la butte de Montaudran, dite aussi de Jolimont. Toulouse se situe aussi dans une position de carrefour commercial et de communications (vers les Pyrénées du centre et de l'ouest par la vallée de la Garonne, vers les Pyrénées de l'est par la vallée de l'Ariège, vers l'océan Atlantique par la vallée de la Garonne et vers la Méditerranée via la trouée de Lespinet et la vallée de l'Hers-Mort). D'autres éléments jouent sur l'implantation de la ville comme la présence d'éminences en rive droite pouvant servir de réduits défensifs en cas de besoin (butte de Montaudran : $200 \mathrm{~m}$ et colline de Pech David : $260 \mathrm{~m}$ ) et, bien entendu, la proximité de la Garonne pouvant tout à la fois alimenter les riverains en eau potable, fournir l'énergie ou le fluide nécessaires à diverses activités artisanales (meunerie, 


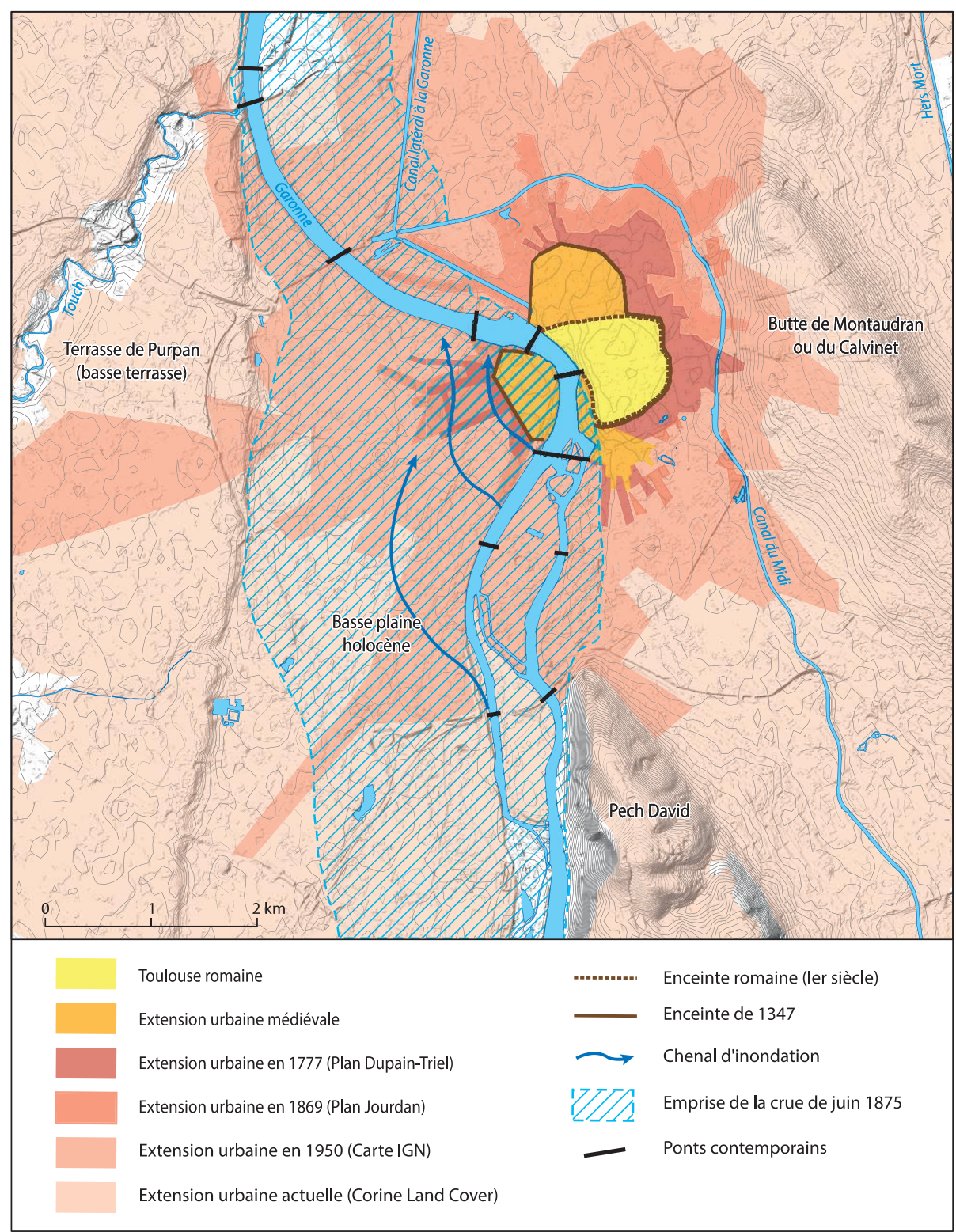

tanneries, draperies...), servir de voie de communications et de transport (bois, minerais et minéraux des Pyrénées ; grains, vins, sel et poissons des régions de plaine ou des côtes atlantiques et méditerranéennes) [fig. 1].

Le site de Toulouse est donc celui, courant en moyenne Garonne, d'un méandre bordé sur sa rive concave (rive droite) par un palier alluvial insubmersible dominé par la colline de Montaudran, et sur sa rive convexe (rive gauche) par la basse plaine holocène submersible, la Garonne ayant d'ailleurs tendance à « tirer tout droit » et à recouper le lobe du méandre lors des plus grandes inondations. Prudemment d'ailleurs, la ville romaine s'est installée en rive droite, sur le palier alluvial surplombant d'une quinzaine de mètres le lit de la Garonne. Elle s'est ensuite étendue en étoile à partir du Moyen Âge, vers l'amont, vers l'aval et vers l'ouest sur la basse plaine holocène (quartier Saint-Cyprien), s'exposant alors aux destructions lors des inondations les plus graves.

Les îles constituent également

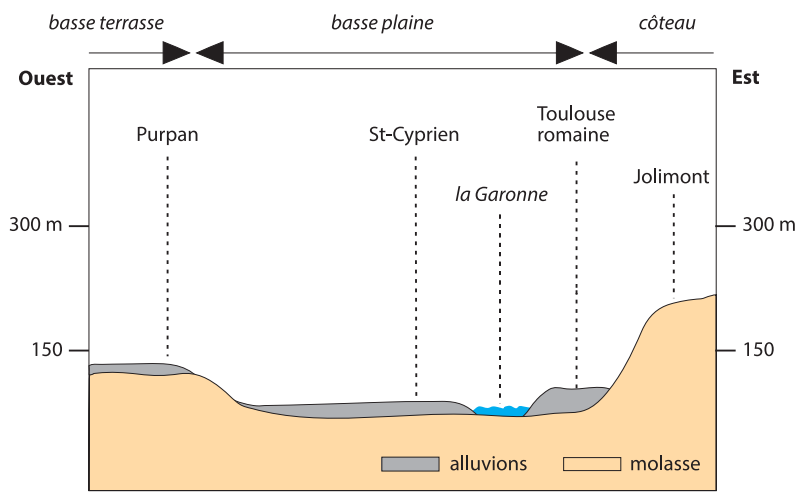

Fig. 1 - Le site de Toulouse

Source : SRTM, BDTOPO, Marconis, 1996 un élément du paysage façonné par le cours d'eau. Rares jusque-là, elles se multiplient à partir de la confluence avec l'Ariège, une dizaine de kilomètres à l'amont de Toulouse, notamment entre le bras inférieur et le bras supérieur de la Garonne : on peut y voir la conséquence du doublement de la charge alluviale lié à la confluence toute proche de l'Ariège, associé à une rupture de charge de la Garonne dont la pente passe de 1,53 \% à 0,7 \% (SMEPAG, 1988), ou encore du matériel détritique fourni sporadiquement par les « falaises » fluviales vives qui échancrent les collines molassiques du Volvestre et du Lauragais juste à l'amont, sur les rives droites de la Garonne (depuis Cazères), de l'Ariège (depuis Pamiers) et de l'Hers-Vif (depuis Calmont). 
Tableau 1- L'évolution du nombre et de la géométrie des îles dans la traversée de Toulouse entre l'île du Ramier et le Bazacle

\begin{tabular}{|l|r|r|r|r|}
\hline & \multicolumn{1}{|c|}{1680} & \multicolumn{1}{c|}{1774} & \multicolumn{1}{c|}{1847} & \multicolumn{1}{c|}{1982} \\
\hline Nombre d'îles & 17 & 9 & 9 & 4 \\
\hline Superficie totale & $25 \%$ & $24 \%$ & $25 \%$ & $17 \%$ \\
\hline Longueur de berges incluant celles des îles & $11400 \mathrm{~m}$ & $9500 \mathrm{~m}$ & $9600 \mathrm{~m}$ & $7200 \mathrm{~m}$ \\
\hline
\end{tabular}

Source : M. Fortuné, 1988

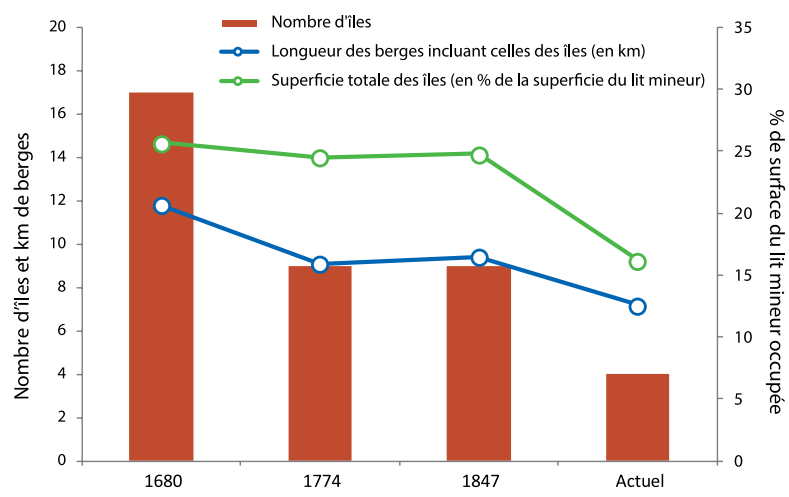

Ces îles, aujourd'hui réduites à cinq, ont été bien plus nombreuses par le passé (tableau 1), en raison sans nul doute d'une dynamique hydrosédimentaire différente (charge sédimentaire plus élevée, crues plus fréquentes et plus intenses...), mais aussi très vraisemblablement en conséquence des interventions massives des sociétés riveraines dans le lit mineur (stabilisation des berges, aménagements hydrauliques...)

Ce contexte géographique a généré trois types de paysages fluviaux « naturels » : une berge peu encaissée en rive gauche et donc prioritairement inondée en cas de crue débordante ; une berge plus haute en rive droite, ménagée soit contre le palier alluvial insubmersible au droit de Toulouse, soit venant buter sur le pied de la falaise fluviale du Pech-David à l'extrême amont de la ville ; et enfin, les paysages rivulaires bas et arborés des îles. Les crues, et en

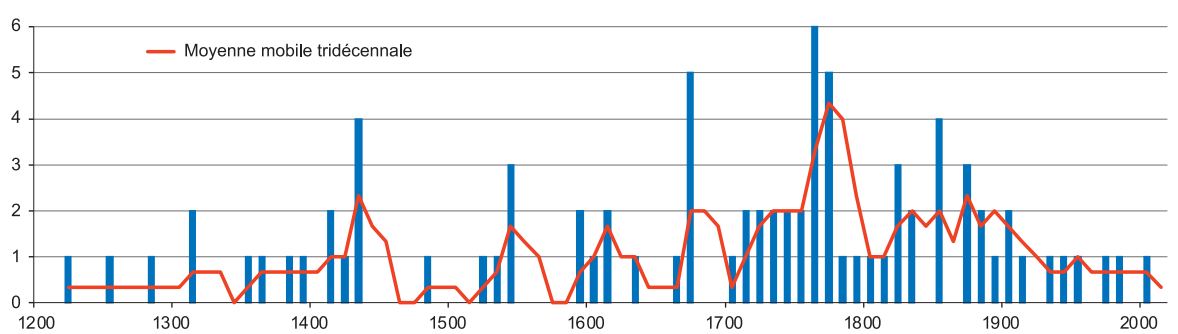

Fig. 2 - Les inondations de la Garonne à Toulouse depuis le xIII ${ }^{\mathrm{e}}$ siècle Source : Antoine, 2006

particulier les plus grandes, sont parfois venues modifier temporairement ou définitivement ces paysages.

\section{Les retouches de détail : les inondations à l'ouvre}

Singulière également est la situation de Toulouse face aux crues et inondations, localement dénommées aygat. La concentration du réseau hydrographique garonnais et la remarquable convergence de la Garonne et de ses affluents placent Toulouse dans le «tuyau » d'un entonnoir de $10000 \mathrm{~km}^{2}$ collectant les eaux des Pyrénées ariégeoises et garonnaises et de leur piémont. Les crues sont donc généralement brutales et atteignent de grandes hauteurs pour une situation de piémont : les grandes crues nées dans les Pyrénées garonnaises et ariégeoises atteignent Toulouse en 10 à $12 \mathrm{~h}$ avec des vitesses de montée de crue de $20 \mathrm{~cm} / \mathrm{h}$ pouvant atteindre $50 \mathrm{~cm} / \mathrm{h}$ (DDT31, 2011), et dépassent $4 \mathrm{~m}$ à partir de la fréquence trentennale $(4,57 \mathrm{~m}$ en février $1952 ; 4,31$ en mai 1977 ; 4,38 en juin 2000). Leur alimentation est essentiellement pluviale même si la fonte nivale a pu participer à certains événements, à l'image du plus dramatique d'entre eux le 23 juin 1875 ou encore de la plus récente en juin 2013.

Depuis les analyses de M. Pardé dans les années 19301950 , on a pris l'habitude de distinguer trois types de crues, en fonction de la direction des flux pluviogènes, des secteurs du bassin générateurs des crues et des saisons de manifestation. Les crues océaniques pyrénéennes, plutôt de printemps, naissent d'averses exacerbées par l'altitude sur les hauts bassins versants pyrénéens, peuvent y rester confinées (juin 2013) ou se propager jusqu'en plaine (juin 1875, mai 1977, juin 2000). Les crues océaniques classiques, habituellement hivernales, gonflent 
Tableau 2- Les grandes inondations de la Garonne à Toulouse

\begin{tabular}{|c|c|c|c|c|}
\hline Date & Hauteur & Débit estimé & Victimes & Dégâts \\
\hline 5 avril 1523 & & & & $\begin{array}{r}\text { Pont Vieux et majorité } \\
\text { des maisons de l'île de } \\
\text { Tounis emportés }\end{array}$ \\
\hline $\begin{array}{r}15 \text { janvier } \\
1599\end{array}$ & & & & $\begin{array}{r}\text { La plupart des maisons } \\
\text { de l'île de Tounis } \\
\text { détruites, Saint-Cyprien } \\
\text { isolé }\end{array}$ \\
\hline 4 juillet 1678 & & & & $\begin{array}{c}\text { Tous les ponts emportés } \\
\text { à Toulouse et à l'amont }\end{array}$ \\
\hline $\begin{array}{r}9 \text { juin } 1712 \\
\text { Aygat de San } \\
\text { Barnabé }\end{array}$ & & & Plusieurs morts & $\begin{array}{r}400 \text { maisons détruites à } \\
\text { Saint-Cyprien et } 30 \text { sur } \\
\text { l'île de Tounis }\end{array}$ \\
\hline $\begin{array}{r}11-12 \\
\text { septembre } \\
1727\end{array}$ & 7,20 (Tounis) & $5500 \mathrm{~m}^{3} / \mathrm{s}$ & 54 morts & 448 maisons détruites \\
\hline $\begin{array}{r}5 \text { avril } 1770 \\
\text { Aygat dets } \\
\text { Raméous }\end{array}$ & $6 \mathrm{~m}$ & $4700 \mathrm{~m}^{3} / \mathrm{s}$ & & 700 maisons emportées \\
\hline $\begin{array}{r}17 \\
\text { septembre } \\
1772\end{array}$ & $\begin{array}{r}6,65 \mathrm{~m} \\
\text { (7,50 à Tounis) }\end{array}$ & $5700 \mathrm{~m} 3 / \mathrm{s}$ & Plus de 50 morts & 100 maisons détruites \\
\hline Mai 1827 & $5,90 \mathrm{~m}$ & $4700 \mathrm{~m}^{3} / \mathrm{s}$ & & \\
\hline 30 mai 1835 & $6,35 \mathrm{~m}$ & $5200 \mathrm{~m}^{3} / \mathrm{s}$ & Plusieurs morts & 48 maisons détruites \\
\hline Juin 1855 & $6,10 \mathrm{~m}$ & $4900 \mathrm{~m}^{3} / \mathrm{s}$ & & \\
\hline $\begin{array}{r}23 \text { juin } 1875 \\
\text { Aygat de San } \\
\text { Joan }\end{array}$ & $8,32 \mathrm{~m}$ & $7000 \mathrm{~m}^{3} / \mathrm{s}$ & 209 morts & $\begin{array}{r}25000 \text { sans-abri, } 1460 \\
\text { bâtiments détruits }\end{array}$ \\
\hline 2 février 1952 & 4,77 (Tounis) & $4350 \mathrm{~m}^{3} / \mathrm{s}$ & & \\
\hline
\end{tabular}

Source : Lafaille, 1687 ; Serret, 1900 ; Chalande, 1912 ; Galabert, 1918 ; SMEPAG, 1989

de Tours (Serret, 1900), les premières mentions circonstanciées d'inondations dans les archives ou chez les chroniqueurs datent de 1281 (Lafaille, 1687 ; Chalande, 1912 ; Galabert, 1918). Certaines furent particulièrement dramatiques, notamment au XviII ${ }^{\mathrm{e}}$ siècle : ainsi de la plus grande connue survenue le 23 juin 1875 , ou encore de celles du 17 septembre 1772 et des 11-12 septembre 1727 qui faisaient référence jusque-là. En moins tragique, d'autres inondations ont néanmoins fortement marqué les esprits et le territoire (tableau 2). Enfin il y a le bruit de fond des crues plus ordinaires, dont la dernière survenue en juin 2000.

L'impact paysager direct de ces crues a été plus ou moins fort mais rarement durable. Certes les plus grandes crues ont détruit de nombreuses maisons et bâtiments d'exploitation, des ponts et des routes, laissé une gangue épaisse de boue et de vase, échoué des débris divers (bois, mobilier, cadavres d'animaux...), raviné les berges... Mais ces dégâts, quoique parfois considérables, étaient finalement assez rapidement effacés du

généralement les cours aval, alimentées par des averses continues et généralisées sur l'ensemble du bassin (décembre 1981, janvier 2009). Enfin, c'est plutôt en automne que prennent place les crues méditerranéennes qui, quoique naissant primitivement dans la partie orientale du bassin (bassins de l'Ariège/Hers Vif, du Tarn amont voire du Lot), peuvent donner lieu à de graves submersions sur le bassin moyen et aval (mars 1930, décembre 1996). En réalité, les crues de la Garonne présentent souvent des caractères mixtes et les saisons de survenance ne sont pas toujours respectées. Ce qui n'exclut pas par exemple la concomitance hautement cyndinogène d'une crue océanique pyrénéenne et d'une crue méditerranéenne.

La Garonne connaît l'une des chroniques de crues les plus anciennes en Europe (fig. 2 et tableau 2). Sans remonter à l'évocation de la crue de 580 par Grégoire paysage. Si on exclut les traits de crue commémoratifs (une quinzaine pour la crue de 1875), le paysage de l'inondation proprement dit est un paysage éphémère. Par contre, les effets géomorphologiques des grandes crues ou de la succession des crues, petites ou grandes, sont plus durables. Ainsi, la « simplification » du paysage du lit mineur (diminution de la sinuosité générale, réduction du nombre d'îles...) évoqués supra est en partie au moins un effet - notable et durable -, de la diminution des grandes crues à fort potentiel morphogène et de transfert sédimentaire. De même, le paysage de «falaises » fluviales qui échancrent les collines du Pech-David est aussi le résultat des grandes crues historiques, venues saper la base du versant de rive droite à l'amont immédiat de la ville. C'est également aux grandes crues des $\mathrm{XVII}^{\mathrm{e}}$ $\mathrm{xvIII}^{\mathrm{e}}$ siècles que l'on doit l'apparition des atterrissements du quai des Ormes et leur soudure progressive à la rive 
gauche, conduisant à une réduction considérable de la largeur du lit mineur à l'amont du Pont-Neuf.

Finalement, sauf exception ${ }^{2}$, le paysage de l'inondation est une construction moins hydrogéomorphologique qu'anthropique. Malgré leur brièveté, les épisodes d'inondation n'en ont pas moins conduit la société toulousaine à intervenir sur les berges pour s'en protéger, façonnant durablement les paysages fluviaux urbains toulousains et participant ainsi à leur fabrique.

\section{II - La part des sociétés riveraines : la dialectique de l'utile et du beau}

Même si les épisodes de crues et d'inondation sont brefs, ils frappent durablement les esprits de ceux qui les subissent dans les « basses terres » de l'île de Tounis ou du faubourg Saint-Cyprien. L'histoire de la fabrique des paysages fluviaux urbains toulousains est donc aussi liée aux réponses apportées par les élites toulousaines. Notables, magistrats et édiles occupent généralement la rive droite, hors d'eau, et pratiquant une forme d'évergétisme, font construire des ouvrages visant à protéger les habitants de la rive gauche (Valette, Carozza, 2013).

\section{La mise en place progressive du front d'eau fluvial ( $\mathrm{XVII}^{\mathrm{e}}$-XIX ${ }^{\mathrm{e}}$ siècles)}

Les paysages actuels du front fluvial en centre-ville résultent de la superposition d'aménagements à vocation différente au cours du temps, mais qui ont en commun le même matériau, la brique rose toulousaine. À côté des réussites et de projets aboutis, le front fluvial est aussi l'objet de tentatives avortées et d'échecs de l'aménagement qui s'étendent du $\mathrm{XvII}^{\mathrm{e}}$ siècle jusque à la fin du XIX ${ }^{\mathrm{e}}$ siècle (fig. 2).

\section{Une exigence humanitaire : protéger les populations du faubourg Saint-Cyprien}

Le premier aménagement d'ampleur pour lutter contre les crues et les inondations qui soit connu date de 1601. Il s'agit d'un remblai de $540 \mathrm{~m}$ de longueur dont le but était de protéger en rive gauche le quartier Saint-Cyprien, le plus vulnérable et où sont historiquement dénombrées

2 Tels par exemple les déplacements successifs de la confluence Ariège-Garonne à Portet-sur-Garonne depuis le XVIII ${ }^{\mathrm{e}}$ siècle (voir M. Lorillard, 1970). la grande majorité des victimes lors des inondations (Fortuné, 1988). En effet, ce faubourg était régulièrement inondé par la Garonne qui tirait très souvent « tout droit » dans le lobe du méandre toulousain lors des crues, et d'autant plus facilement que ce faubourg se trouvait en quelque sorte insularisé car ceint depuis le Moyen Âge par un profond fossé de défense et la Garonne. La grande largeur du remblai témoigne des difficultés rencontrées pour maintenir l'ouvrage face aux courants du fleuve. Après quelques tâtonnements et améliorations le remblai devint la digue du cours des Ormes, qui sera absorbée un siècle plus tard par ce qui deviendra le cours Dillon actuel. Cette digue est prolongée en aval par plusieurs bâtiments dont les murs extérieurs, plongeant directement dans le lit du fleuve, font également office de digues de protection. Vers la fin du XvII ${ }^{\mathrm{e}}$ siècle et le début du XviII ${ }^{\mathrm{e}}$ siècle, l'hôtel-Dieu Saint-Jacques et l'hôpital général Saint-Joseph de la Grave accueillent pèlerins, malades, aliénés et pauvres de la ville ou simplement de passage (Taillefer, 2005). Plus tard, au XviII ${ }^{\mathrm{e}}$ siècle, le cours des Ormes est remplacé par une digue en briques s'appuyant sur le Pont-Neuf et prolongée vers l'amont jusqu'à la porte de Muret. Après sa reconstruction entre 1758 et 1762, l'ancien cours des Ormes devient le cours Dillon. La protection du quartier Saint-Cyprien est parachevée en 1779 par la fermeture d'une brèche entre l'hôtel-Dieu et l'hôpital Saint-Jacques.

\section{Un projet urbain : protéger et embellir le centre} ancien

Durant le $\mathrm{XvII}^{\mathrm{e}}$ siècle, les travaux de protection se concentrent sur la rive gauche et le quartier SaintCyprien. Sur l'autre rive, en bordure du centre ancien, le paysage fluvial se matérialise par une succession de maisons « les pieds dans l'eau », notamment sur la rive ouest de l'île de Tounis, encore isolée de la berge droite par le bras de la Garonnette. La digue du cours des Ormes et les murs extérieurs des hôpitaux rejettent le courant sur cette rive droite et y provoquent des érosions. Dans la seconde moitié du XviII ${ }^{\mathrm{e}}$ siècle, un trio composé de Louis de Mondran, urbaniste et économiste, et de deux directeurs des travaux publics de la province de Languedoc, François de Garipuy et Joseph-Marie de Saget, est à l'initiative d'un aménagement complet des berges de rives droite et gauche de la Garonne entre le Pont-Neuf et le Bazacle. "Le XviII ${ }^{\mathrm{e}}$ siècle est vraiment celui des grands travaux d'aménagement et de protection de la ville contre la Garonne " (Fortuné, 1988). Ces travaux consistent en l'aménagement de quais pour favoriser la navigation et le commerce fluvial, doublés d'un mur pour lutter contre les érosions en rive droite et les inondations en rive gauche. 
Cet ensemble est paré de trois ports : ports du Vidou et de la Daurade en rive droite et le port Viguerie en rive gauche. L'ensemble des travaux est réalisé entre 1741 et 1789, encouragés sans nul doute par la survenue de certaines des plus grandes crues connues de la Garonne en $1750,1765,1770$ et 1772 notamment. Tous ces aménagements ont été conçus non seulement pour protéger la ville mais aussi pour l'embellir. J.-M. Saget fait édifier des maisons au-dessus des quais, en en reprenant les mêmes matériaux. Les façades sont rythmées par de grandes arcades se succédant entre la place Saint-Pierre et le port de La Daurade. Cet alignement de quais et de belles demeures est devenu aujourd'hui un des paysages identitaires de la ville de Toulouse. Il faut ajouter à tous ces aménagements la construction du canal de Brienne en 1768 , qui permet la liaison entre la Garonne et le port de l'Embouchure où se connectent le canal du Midi et le canal latéral.

\section{Sauver l'île de Tounis et ses industries}

L'histoire de l'île de Tounis est intimement liée à la Garonne : occupée par le petit peuple lié aux activités artisanales tributaires du fleuve (meuneries, tanneries, teintureries, lavandières...), elle était régulièrement touchée par les crues de la Garonne, même moyennes. Elle a fait l'objet de tentatives de protection des berges longtemps restées sans réelle efficacité, en particulier au niveau de la rive droite de la pointe sud de l'île. La construction d'un mur de quai est ainsi ordonnée par les Capitouls en 1612, sans suite. Tant et si bien qu'en 1624, « les inondations de la rivière commencèrent d'emporter une partie desdites maisons [...]» (Archives municipales de Toulouse, DD 142). Pour solutionner le problème, une digue est construite mais très rapidement mise à mal par les inondations de 1635, 1639 et 1667 (Laffont, 1997). Face à ces dégradations successives, l'idée est alors de se concentrer sur la construction d'un quai, entamée en 1668 mais qui ne verra finalement jamais le jour (Devic et Vaissète, 1746, p. 179). Après le passage des inondations de 1670 et 1672, l'île reste sans défense. Elle le restera encore longtemps, d'autant plus qu'en 1713, la réfection et le rehaussement de la chaussée du Bazacle viennent élever le niveau de l'eau du fleuve. Par rétroaction négative liée à la présence de la digue du cours des Ormes sur la rive opposée, les eaux de la Garonne provoquent de nombreuses et régulières dégradations sur l'île de Tounis. Dans la seconde moitié du XVIII ${ }^{\mathrm{e}}$ siècle, la protection de l'île était envisagée dans le projet initial de Saget mais elle n'a jamais été réalisée faute de moyens. Un peu plus tard, les protestations des

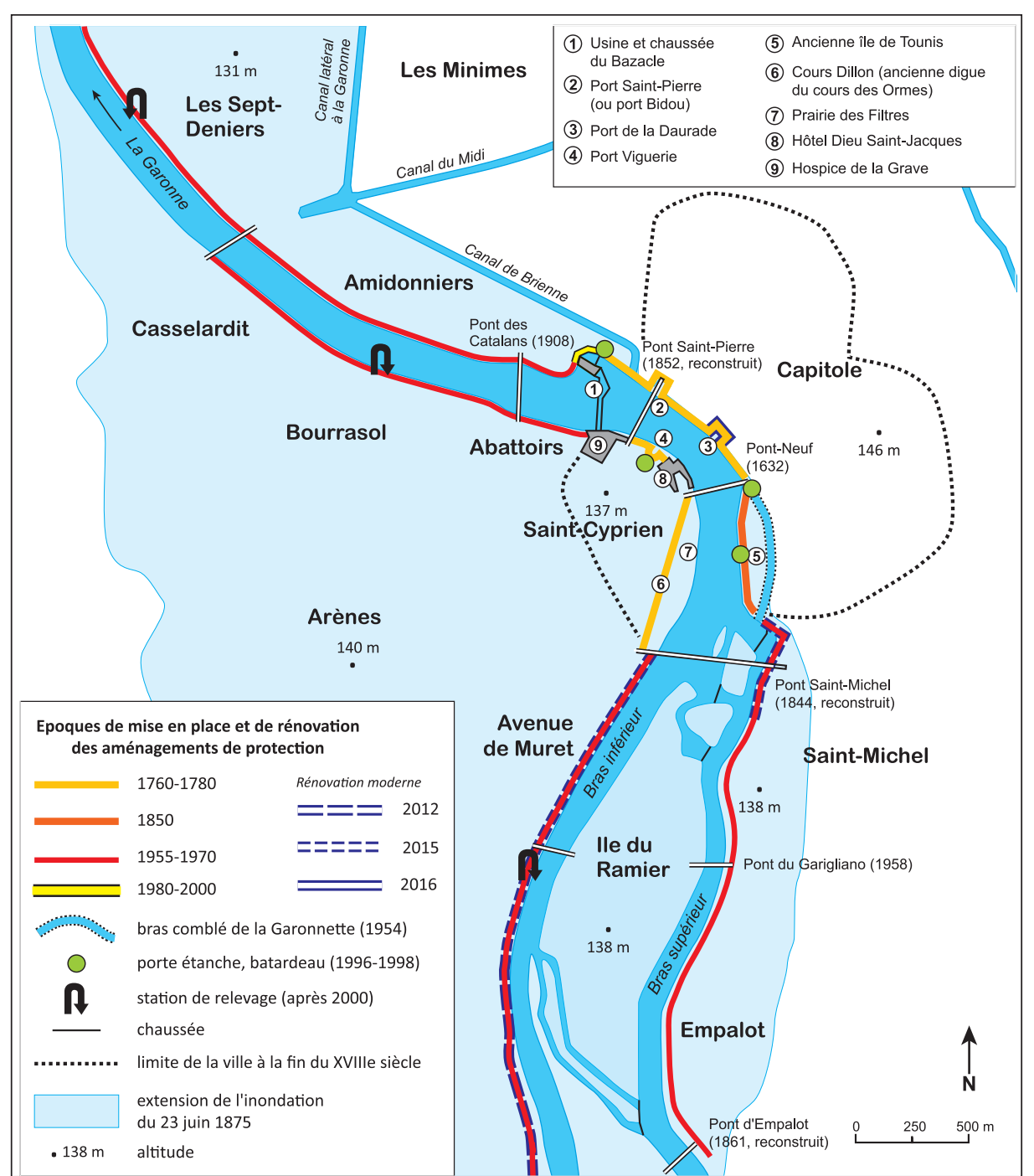

Fig. 3 - Aménagements de protection contre les inondations 
Tounisiens s'accentuent et la décision de protéger l'île est prise au cours du XIX ${ }^{e}$ siècle. Les travaux débutent en 1850 et se terminent en 1866, quasiment sur le modèle de ce qui avait été réalisé un siècle plus tôt (Arrouy, 2005). Les travaux consistent en l'établissement d'un quai situé sur le bras principal de la Garonne, prolongé d'un pont de halage reliant l'île de Tounis à l'île Saint-Michel. Au-dessus du quai, l'idée d'une valorisation immobilière est reprise, le plan initial prévoyant notamment de rattacher l'île à la rive droite. Les habitants s'étant énergiquement opposés à ce projet, l'île de Tounis resta une île et le bras de la Garonnette sera conservé jusqu'au milieu du $\mathrm{Xx}^{\mathrm{e}}$ siècle. Les travaux menés au XIX ${ }^{\mathrm{e}}$ siècle reprennent l'esprit de ceux du xviII ${ }^{\mathrm{e}}$ siècle, de même que les matériaux utilisés. Ainsi est achevé le célèbre front fluvial toulousain de briques roses.

Du XVII ${ }^{\mathrm{e}}$ au XIX ${ }^{\mathrm{e}}$ siècles, la ville de Toulouse s'est donc dotée de dispositifs de protection contre les inondations tant sur la rive gauche que sur la rive droite. La façade fluviale est ainsi complètement redessinée et, passés les travaux sur l'île de Tounis, les paysages fluviaux urbains du centre ancien se figent. L'ensemble des projets de protection contre les inondations a créé un véritable front fluvial toulousain qui, au-delà de sa dimension utilitaire, a également une ambition esthétique et devient une parure architecturale pour la ville.

\section{De la brique au béton ou la relégation du fleuve (1937-1971)}

Durant la première moitié $\mathrm{du} \mathrm{xx}^{\mathrm{e}}$ siècle, la ville de Toulouse connaît un doublement de sa population (qui passe de 150000 habitants au début du siècle à 320000 en 1960). La progression de l'urbanisation en zone inondable qui en découle (rive gauche notamment) pose la question de la protection de la ville et du prolongement/exhaussement des digues des XVIII ${ }^{\mathrm{e}}$ et XIX ${ }^{\mathrm{e}}$ siècles. D'autant que les désastres de la crue de juin 1875, la plus grande connue à Toulouse avec 8,32 m à l'échelle du Pont-Neuf, a montré son extrême vulnérabilité. Se succèdent alors de nombreux projets de protection imaginés par les ingénieurs des Ponts et Chaussées - Lanteirès en 1876, Gros en 1877, Vidalot en 1884, Eyriaud Devergnes en $1899 \ldots$-, avant que ne soit créé en 1911 le service spécial d'étude contre les inondations de Toulouse, confié à l'ingénieur Pendariès. Ce dernier élaborera quatre avant-projets avant que le cinquième, revenant au projet Lantériès de 1876 en préconisant un endiguement général, ne soit adopté en $1933{ }^{3}$ et devienne la référence. Pour autant, malgré un début des travaux en 1937, il faudra attendre la crue « seulement» trentennale de février 1952, pour que les travaux d'endiguement modernes soient véritablement lancés en 1954 (Piquemil, 2001).

C'est ainsi que vont être érigées, non sans mal et en commençant par l'amont de la ville, de hautes digues en béton, calibrées sur la crue de 1875. Entre 1955 et 1959, sont bâties les digues d'Empalot et Saint-Michel en rive droite et de l'avenue de Muret en rive gauche. Si elles protègent les rives droite et gauche urbanisées, on renonce à protéger l'île du Ramier qui reste soumise aux inondations. En aval du Bazacle, des lourdeurs administratives font que les travaux sont plus tardifs. Les digues des Amidonniers et des Sept-Deniers sont ainsi construites entre 1964 et 1967. Sur la rive gauche, entre les Abattoirs et Bourrasol-Casselardit, les travaux d'endiguement sont menés de 1968 à 1971, ici aussi retardés par le refus de l'État à participer au financement. En effet, le statut des digues de Toulouse est particulier : alors qu'elles appartiennent habituellement aux propriétaires privés ou aux communes, $80 \%$ du linéaire des digues toulousaines appartient à l'État (12 500 m) parce qu'il en a été le constructeur après la crue de $1875^{4}$.

Ainsi, au début des années 1970, « le lit de la Garonne a été enfermé dans un système de digues en béton, depuis les ponts d'Empalot jusqu'au pont de Blagnac » (CUIET, 1993), soit sur 8 km dans la traversée de Toulouse. Les matériaux utilisés et la hauteur des ouvrages tranchent singulièrement avec les ouvrages réalisés les siècles précédents. Le béton et la verticalité des ouvrages ont pour objectif, avant toute chose, de contenir l'inondation : l'utile a pris le pas sur le beau. Les digues sont de véritables remparts isolant la ville du fleuve et conférant au paysage une incontestable et peu séduisante artificialité. On notera que cette artificialisation a pu aller jusqu'à la disparition totale du paysage fluvial avec le comblement du bras de la Garonnette en 1954 et sa transformation en vulgaire rue.

3 L'échec des projets présentés entre 1876 et 1933 tient notamment à la radicalité de certaines des solutions proposées, et massivement rejetées par les toulousains ou leurs édiles : dérivation de la Garonne au milieu de Saint-Cyprien, destruction de l'hôtel-Dieu et du PontNeuf, enlèvement de la prairie des Filtres...

4 (http://www.toulouse-inondation.org) 


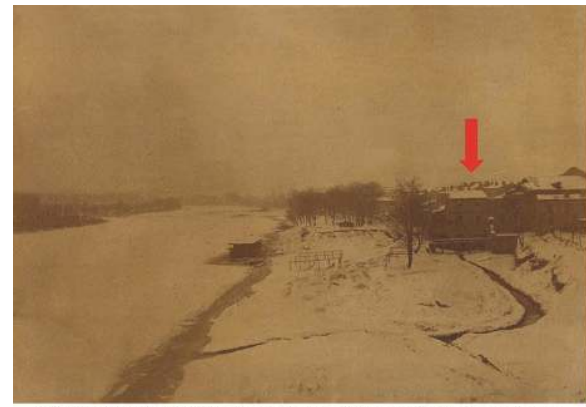

Fin XIXe siècle (Muséum d'Histoire Naturelle de Toulouse, Trutat)

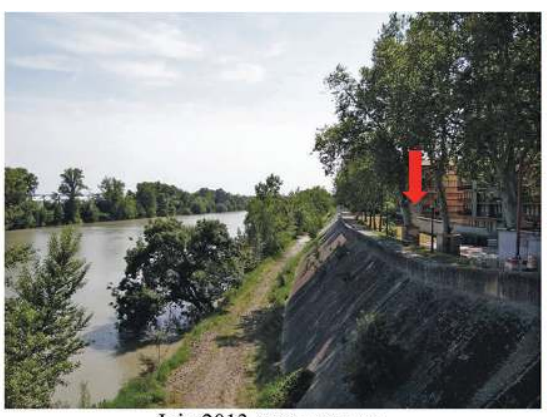

Juin 2013 (Philippe Valette)

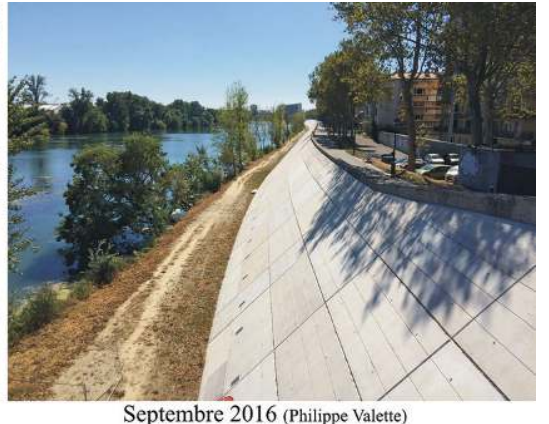

Septembre 2016 (Philippe Valette)

Fig. 4 - Évolution des paysages fluviaux urbains en amont du pont Saint-Michel entre la fin du xix siècle et aujourd'hui. Le moulin Vivens disparaît au profit de la construction de digues en béton, qui ont été confortées en 2014-2015

Source : Muséum d'histoire naturelle de Toulouse, Trutat/Philippe Valette

\section{Parachever la protection de l’agglomération (1990-2016)}

Les années 1990 sont l'occasion d'un certain nombre de travaux qui finalisent la protection de la ville face aux inondations. Dans la veine des ouvrages construits après 1952, sont construites la digue de Ginestous qui prolonge vers l'aval au-delà du pont de Blagnac la digue des SeptDeniers (1997), et celle du Bazacle réalisée en 2000. Ces ouvrages, notamment le premier, ont un impact certain sur le paysage fluvial, mais ils montrent aussi, et sans céder à leur fonction de protection, un effort d'intégration au paysage : leur hauteur ne dépasse pas $5,50 \mathrm{~m}$, la municipalité a refusé catégoriquement un revêtement en béton et ils font l'objet de tentatives de végétalisation.

D'autres travaux ne sont que de simples retouches à un système censé contenir une crue plus que centennale, sans impact majeur ou supplémentaire sur le paysage fluvial. On citera la surélévation du cours Dillon à SaintCyprien, l'installation de stations de relevage des eaux pluviales (avenue de Muret et boulevard Wagner en rive gauche, Sept-Deniers en rive droite), la pose de portes étanches métalliques (au port Viguerie, à l'aval de la rue de la Garonnette...) et de batardeaux mobiles (quai de Tounis), etc.

Enfin, un programme décennal de confortement des digues de Toulouse (2009-2020) a été engagé en 2012, en parallèle du plan de prévention des risques inondation approuvé le 10 décembre 2011. Ce programme de 40 millions d'euros est financé à hauteur de $51 \%$ par l'État, 40 \% par la ville de Toulouse et $9 \%$ par la région, dans le cadre du transfert de propriété des digues de
Toulouse de l'État vers la ville ${ }^{5}$. Il a notamment déjà donné lieu à la reconstruction ou au confortement des digues en terre de Langlade (2012) et de l'avenue de Muret (2014-2015 ; cf. fig. 3), la réfection d'un mur de protection à l'hôtel-Dieu en 2014 et la rénovation du port de la Daurade en $2016{ }^{6} \ldots$ Le paysage fluvial préexistant n'en est pas pour autant modifié, tout juste est-il rajeuni par l'emploi des matériaux initiaux à l'état neuf (briques foraines pour le mur de l'hôtel-Dieu, dalles de béton pour l'avenue de Muret).

Concrètement aujourd'hui, la ville s'est dotée d'un dispositif de protection dimensionné pour une crue de type 1875, de récurrence pluri-centennale, mais à quel prix : variété et hétérogénéité des différentes générations de digues, artificialisation et relégation hors de l'espace urbain du paysage « naturel » fluvial, retranchement de la ville derrière ses digues...

\section{III - De la protection aux loisirs}

La fabrique des paysages fluviaux urbains toulousains est liée à ce long héritage de politiques publiques mises en place pour lutter et se défendre contre les inondations. Partout, les digues en brique rose ou en béton corsètent les bords du fleuve.

5 Cf. note 5 ; à terme la propriété du linéaire des digues toulousaines devrait être également répartie entre l'État et la commune de Toulouse.

6 http://www.toulouse-inondation.org/ 


\section{Un paysage marqué par la protection... mais aussi support d'activités ludiques}

Cours Dillon (ancien cours des Ormes), quai de la Daurade, quai de Tounis, quai de la Dalbade, digue de Saint-Cyprien offrent un paysage fluvial urbain homogène. Tous ces ouvrages construits entre le $\mathrm{XvII}^{\mathrm{e}}$ et XIX $^{e}$ siècle ont utilisé la brique rose comme matériau de construction, ce qui contribue à façonner une unité paysagère. Elle tranche sévèrement avec les travaux de la seconde moitié $d u \mathrm{xx}^{\mathrm{e}}$ siècle, où le béton gris casse l'unité chromatique. La géohistoire des paysages fluviaux urbains révèle bien une omniprésence de la volonté de se défendre face aux inondations. Mais, qu'ils soient en brique ou en béton, l'ensemble de ces ouvrages sont construits comme de véritables balcons sur le fleuve, de sorte qu'ils sont devenus un lieu privilégié de promenade pour les toulousains (Valette et al., 2013). Aujourd'hui, les paysages fluviaux urbains liés à la brique du centre ancien sont connus et reconnus de tous, à tel point que les berges de la Garonne font partie des lieux les plus photographiés sur instagram (https://www.busbud.com/ blog/fr/lieux-plus-instagrammes-france/).

Si l'inondation a été créatrice de paysages fluviaux urbains particuliers à Toulouse, de nombreux loisirs se sont exprimés depuis longtemps à proximité de la Garonne à Toulouse. L'ancien cours des Ormes (actuel cours Dillon) est d'abord une digue. À l'origine, il est planté d'une double rangée d'ormes et devient un lieu privilégié de promenade, de repos et de distractions pour les toulousains. Jusqu'au $\mathrm{xx}^{\mathrm{e}}$ siècle, de nombreuses manifestations y sont organisées : fenetra (ou feretra, fête toulousaine, marché), courses cyclistes, théâtre de plein air, boulodrome. Un peu plus tard dans la seconde moitié du XIX ${ }^{\mathrm{e}}$ siècle, le cours Dillon a été associé à la prairie des Filtres car plusieurs îlots ont été rattachés à la berge de rive gauche. Cet espace devient alors une véritable zone d'expansion des inondations mais aussi un lieu privilégié de nombreuses manifestations populaires (école de natation, fête de charité, course de vaches landaises, premiers matches du Stade toulousain, manœuvres militaires, feux d'artifice, foire agricole, promenade, détente...). En 1976, la municipalité y crée un jardin public de 13 ha en plein cœur de ville, dans une période où la mode est plutôt à l'aménagement de voies sur berges. Au début du $\mathrm{xx}^{\mathrm{e}}$ siècle, l'opportunité foncière liée au déplacement de la poudrerie de l'île du Ramier permet la création du parc toulousain d'une superficie de 50 ha. Ce lieu a été très populaire et il est bien représenté dans les cartes postales ou images anciennes. Il était composé d'espaces de promenade, de théâtres de plein air, de kiosque à musique, de café-restaurant et de nombreuses fêtes et bals y étaient organisés. En 1930, le parc toulousain évolue vers de nouvelles pratiques sportives. En 1928, les activités nautiques, la pelote basque et le tennis investissent les lieux (Noé-Dufour, 1998). En 1931, le parc toulousain est réinvesti par la municipalité comme parc d'hygiène et des sports (piscine classée monument historique en 1993 et stadium municipal). L'île du Ramier, située en zone inondable, garde encore la trace de tous ces aménagements dans ses paysages.

Des années 1990 jusqu'à aujourd'hui, après une période de sommeil et d'abandon du fleuve, plusieurs sites ont été valorisés en bord de Garonne, de sorte que les usages de loisirs sont aujourd'hui omniprésents en bord de fleuve. Il faut voir dans ce vaste mouvement l'effet de valorisations qui ont eu lieu ailleurs en France et qui ont valeur d'exemples (Paris, Lyon, Nantes, Bordeaux...). D'ailleurs, aujourd'hui, ce phénomène n'est pas seulement franco-français il est d'ampleur mondiale (Montréal, New York, Londres...).

À Toulouse, il est possible de noter, sans être exhaustifs, plusieurs pratiques de loisirs et des manifestations culturelles diverses sur le fleuve qui marquent les consciences des riverains depuis plusieurs années (CUIET, 1993). Par exemple, en 1995, le festival Rio Loco est créé. Il s'agit de concerts organisés en bord de Garonne (prairie des Filtres), entre la fin juin et le début juillet. Rio Loco existe depuis 20 ans et est un festival populaire, familial où il est possible de chanter, danser, faire la fête en bord de Garonne (fig. 5).

Au-delà de cette manifestation festive, plusieurs festivals artistiques sont aussi organisés sur les berges de la Garonne à Toulouse. Le festival MAP (Mise au Point) existe depuis 2009. Il s'agit d'un rendez-vous annuel d'exposition de photographies dans différents lieux de Toulouse dont les quais de la Garonne (http://www. map-photo.fr/). Les installations sur les quais sont d'accès libre et gratuit et ils embellissent les quais le temps du festival. D'un autre côté, « Garonne expose » est une exposition d'artistes amateurs tous les dimanches sur les quais de la Daurade. Cette initiative existe depuis 2001 (http://www.la-garonne-expose.com/). Enfin, certaines expositions temporaires peuvent magnifier les paysages fluviaux urbains. C'est le cas avec The Fly's Eye Dome de Buckminster Fuller dans le cadre du festival international d'art de Toulouse. Cette œuvre d'art a été installée 

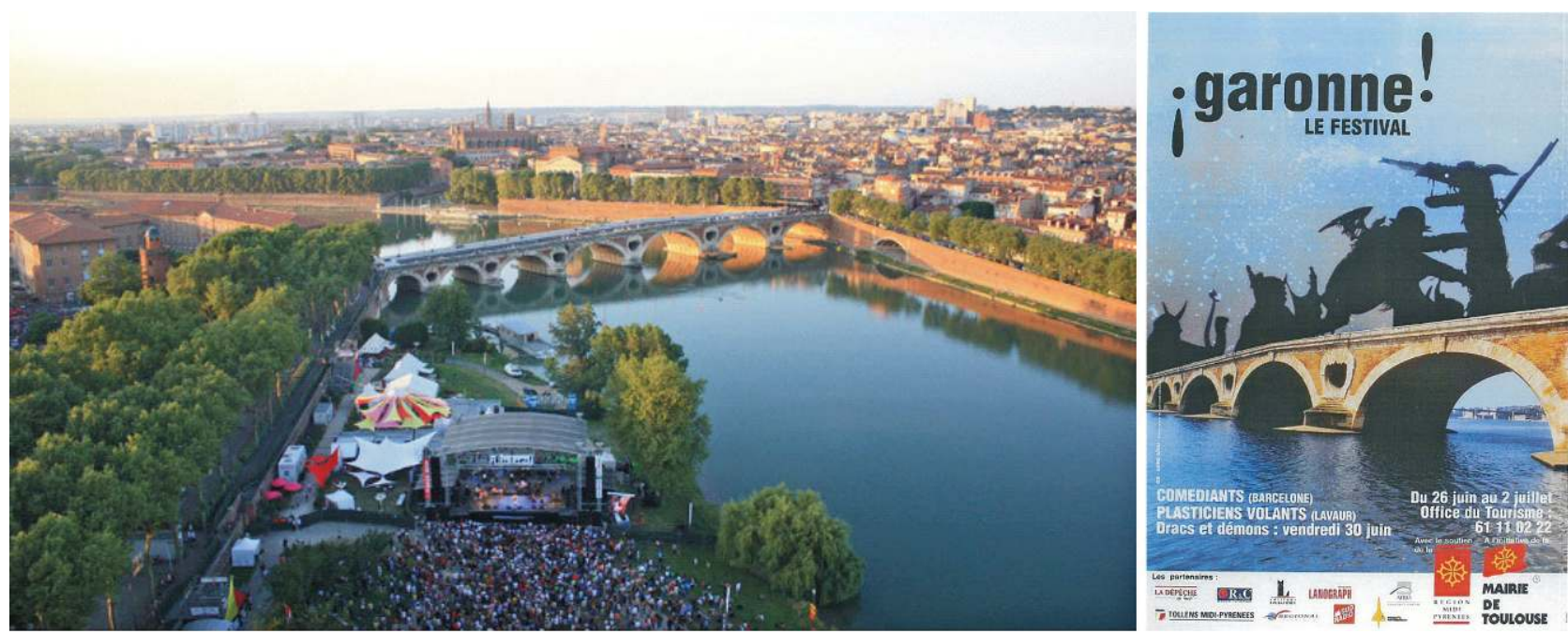

Fig. 5 - Le festival Rio Loco à Toulouse sur la prairie des filtres. Première affiche du festival

Source : http://www.rio-loco.org

sur l'esplanade de l'ancien port de Saint-Cyprien (port Viguerie) en 2013.

On le voit à travers toutes ces initiatives, les paysages fluviaux urbains toulousains sont, depuis quelques années, le support d'une diversité d'usages de loisirs. Le projet de parc Garonne défini par Toulouse métropole depuis 2010 entre également dans cette dynamique.

\section{Un paysage en cours de valorisation : le projet Parc Garonne}

Bien que beaucoup d'événements ludiques et culturels soient temporaires, ils sont aussi récurrents. Depuis les années 2010, la volonté est de valoriser le fleuve non plus à l'échelle du centre ancien, mais aussi à l'échelle de l'agglomération entre la confluence de l'Ariège et Grenade-sur-Garonne (Valette, 2015 ; Papillault et al., 2012). Il faut voir dans ce changement d'échelle d'intervention les effets du projet Grand Paris à la même époque, mais aussi la réussite du retour au fleuve à travers l'exemple bordelais dans les années 2000. Dans ce cadre-là, Toulouse Métropole s'empare de la thématique Garonne et lance des études et une programmation à l'horizon 2030 (CUGT, 2012).

Dans le cadre de cette action, plusieurs objectifs sont poursuivis comme favoriser et mettre en place des cheminements doux (piétons et cyclistes), renforcer les usages liés à l'eau du fleuve (nautisme, navigation), développer des espaces culturels et de convivialité (observatoire, guinguettes), et pour finir valoriser le patrimoine naturel.

Ce projet parc Garonne est ambitieux est vise à donner un nouveau souffle à la valorisation des berges du fleuve. Plusieurs opérations sont programmées d'ici 2020 et parmi elles, la plus ambitieuse est de recréer le parc toulousain sur l'île du Ramier (promenade, fêtes, sport, détente). Une autre vise à réhabiliter le port Viguerie, qui fait l'objet de nombreuses réflexions mais aucune mise en valeur depuis 10 ans. Les travaux de valorisation de ce port sont d'ailleurs en cours de réalisation. Toutes ces initiatives devraient permettre de nouveaux usages, de nouvelles pratiques.

Depuis deux ans, des cheminements doux le long de la Garonne sont balisés sur tout le territoire de l'agglomération. Ils permettent de relier les espaces verts entre eux (Quinze Sols, Blagnac, prairie de Filtres, parc du Confluent ; fig. 6). Les anciens ports du centre ancien sont réhabilités comme pour le port Saint-Pierre ou celui de la Daurade. Depuis 2015, une guinguette temporaire est mise en place le long du quai de Tounis (fig. 6).

Par ailleurs, cette période se caractérise par la construction de plusieurs complexes immobiliers à l'aval (ancienne île du Bazacle, anciens abattoirs) et en amont (ancien quartier du port Garaud), où la vue sur le fleuve devient un argument de vente majeur. La valorisation des berges de la Garonne se traduit donc aussi par un changement architectural sur les berges. Les populations vivant dans ces immeubles peuvent alors bénéficier des 

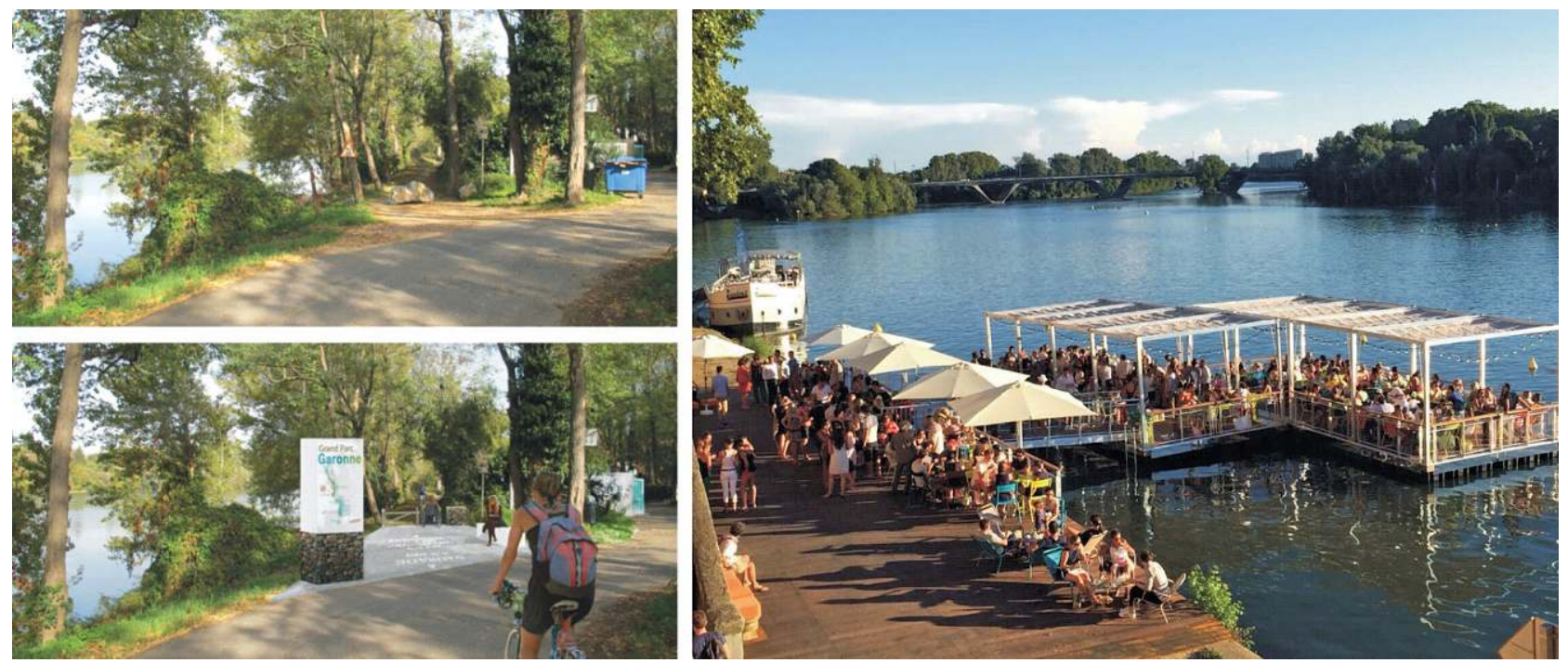

Fig. 6 - Balisage des cheminements doux le long de la Garonne (source : Toulouse Métropole) et la « nouvelle » guinguette

Source: Ph. Valette

aménités paysagères et environnementales liées à la Garonne comme au niveau du jardin Raymond VI où dans l'espace vert de l'ancien bras du Bazacle.

Toutes ces initiatives participent d'un changement de paradigme, opéré à partir des années 1990, et complété par le projet parc Garonne à l'échelle de l'agglomération toulousaine à partir des années 2010. Nous sommes passés d'un fleuve craint et contre lequel il fallait se protéger à un fleuve comme espace de loisirs. Néanmoins, il est à noter que ce changement de paradigme s'opère en même temps qu'un perfectionnement de la protection contre les inondations du fleuve dans le centre ancien. Certes, aujourd'hui, la Garonne est un lieu de ressourcement mais on n'oublie pas qu'elle peut être une source de dangers. Dans le cadre du plan de prévention du risque d'inondation (PPRI), la municipalité de Toulouse crée un site internet (http://www.toulouse-inondation.org/) où la mémoire du risque est privilégiée à travers de nombreux documents anciens. Toulouse Métropole, quant à elle, inventorie les repères de crues (https://www.flickr.com/ photos/toulousemetropole/sets/72157645503003093/).

\section{Perception des paysages fluviaux toulousains par les riverains}

Dans le cadre d'un atelier pédagogique, nous avons passé 100 questionnaires à des riverains sur les bords du fleuve à Toulouse (travaux réalisés dans le cadre du master 1
$\mathrm{GEP}^{7}$. Ce travail nous a permis d'esquisser des réflexions et quelques résultats préliminaires sur la perception des paysages fluviaux toulousains.

Parmi les nombreuses questions du questionnaire, la première était : citez 3 mots qui vous viennent à l'esprit lorsque vous pensez à la Garonne à Toulouse (cf. fig. 7).

Les deux mots qui ressortent du résultat sont «nature » et « beau ». Les questionnés recherchent dans les paysages fluviaux urbains toulousains une image de nature, qualifiés de « beaux », qui est en totale contradiction avec l'artificialité de ces paysages. Dans une moindre mesure, d'autres mots ressortent, comme «fleuve », " paysage », « promenade », « détente », « calme », « soleil », « eau ». Tous correspondent à des aspects appréciables, agréables que les questionnés recherchent à proximité du fleuve. Ces différents éléments permettent d'affirmer que la Garonne à Toulouse est aujourd'hui considérée comme une aménité paysagère. Elle peut être complétée par d'autres termes qui apparaissent dans le nuage de mots comme : « agréable », « tranquille », « reposant », « balade » ou « paisible ». De la même manière, plusieurs pratiques de loisirs apparaissent: " promenade», « sport », «fête », « flâner ». Les 100 questionnaires ont été passés sur l'ensemble des berges en ville : 40 en centre-ville à proximité des dispositifs de défense anciens, 40 sur les digues en béton en amont et aval du

7 Paul Busserole, Hélène Chapelle, Laure Coussout, Laurie Lamigeon, Martin Lemaire, Pierre Marceteau, Gaëlle Mercier, Quentin Merley, Ghislain Poirson. 


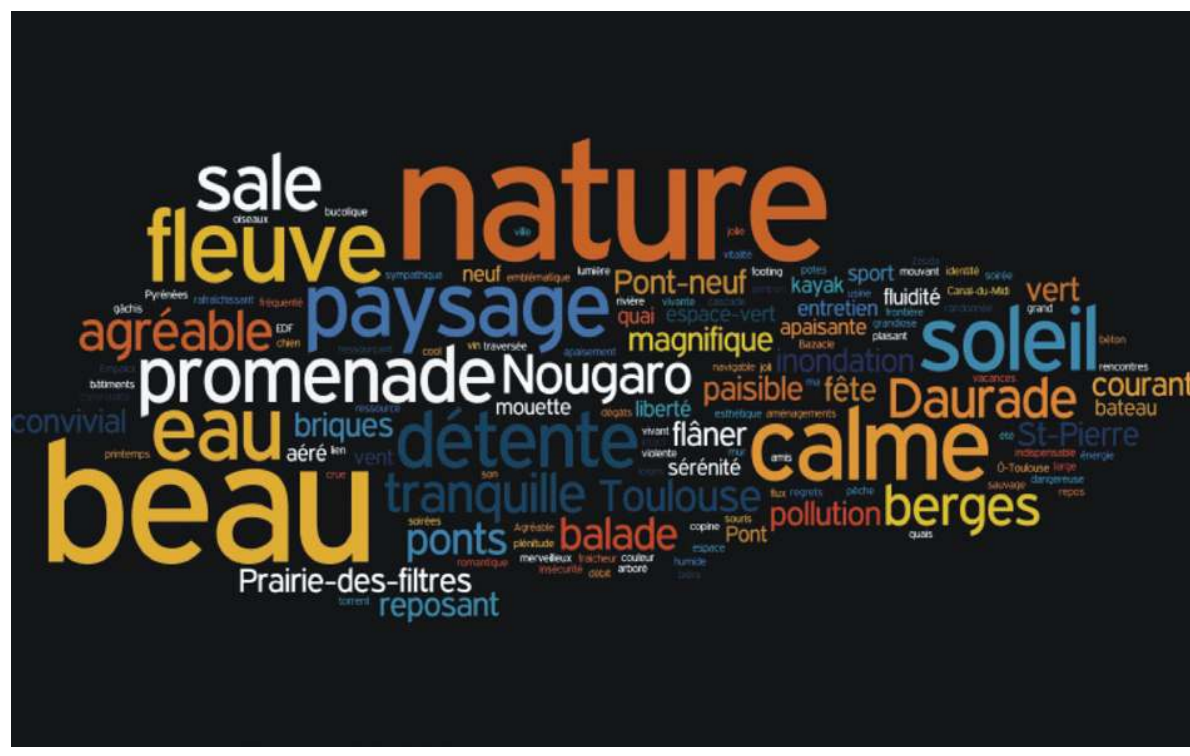

Fig. 7 - Nuage de mots. Résultats à la question : citez 3 mots qui vous viennent à l'esprit lorsque vous pensez à la Garonne à Toulouse

Source : Ph. Valette, 2017

centre et 10 sur l'île du Ramier. Cette précision est importante car dans les résultats on ne trouve pas de mots relatifs à la fonction de protection contre les inondations. Par exemple le mot « digue » n’a jamais été prononcé. Sur les 286 mots au total récupérés, le mot « inondation » a été prononcé 4 fois, « dangereuse » 2 fois, « courant» 4 fois, « dégâts » une seule fois, « aménagement » une fois. Ainsi, l'inondation qui est à l'origine de la fabrique des paysages fluviaux urbains toulousains est quasiment absente des perceptions actuelles des riverains.

D'autre part, dans le cadre de ce questionnaire, une série de 8 photographies ont été montrées aux questionnés et ils devaient répondre à la question suivante : aimez-vous les paysages représentés sur les photographies ci-dessous (note de 0 à 10)?

Les photographies qui représentent un espace vert et les « paysages identitaires » de la ville (quais de briques roses) obtiennent les meilleures notes, respectivement $8,4 / 10$ et 7,8/10. À un niveau moindre, la photographie représentant les loisirs en bord de Garonne obtient $7,5 / 10$ talonnée de près par une image où la ripisylve est très présente (image de la Garonne « sauvage », 7,4/10). À travers ces quatre clichés, c'est tout l'espace de loisirs en reconquête lié à la Garonne qui est représenté et qui obtient les meilleures notes. Les clichés les moins bien notés représentent l'ancien patrimoine industriel (moulin du Bazacle, note de 6,7/10), les digues en béton $(6,2 / 10)$, un parking à voiture sur les berges $(4,2 / 10)$. Enfin, le dernier cliché représentant l'inondation est particulièrement mal noté $(3,9 / 10)$ et confirme que l'inondation n'entre pas dans la représentation des usagers.

Une autre question du questionnaire consistait à demander aux enquêtés les éléments qui leurs paraissaient essentiels dans un paysage fluvial. Quatre éléments reviennent avec force : la vue sur le fleuve, l'accès aux berges, le caractère sauvage/ naturel et un lieu de détente/ loisirs. Ces résultats montrent clairement que les paysages fluviaux urbains sont appréciés en tant qu'aménités avec une importance des aspects ludiques, de détente et d'accès aux berges. Ce qui est recherché c'est aussi un caractère sauvage et naturel tandis que la protection contre les inondations est, encore une fois, assez peu citée par rapport aux autres éléments.

\section{Conclusion}

Ces résultats préliminaires montrent clairement que, pour les usagers, la Garonne à Toulouse est d'abord un espace voué aux loisirs, une aménité paysagère. Il faut voir ici les échos des attentes des habitants d'une nature en ville préservée et renouvelée. La Garonne est alors considérée comme un élément de nature, en contradiction avec l'artificialité des paysages fluviaux. Et pourtant, l'inondation à l'origine de la fabrique des paysages fluviaux urbains toulousains et matérialisation d'un système naturel en fonctionnement est quasiment absente dans les réponses. Cette absence est liée au fait que les inondations sont des épisodes brefs, éphémères dans le temps et, finalement, rares. Pour que ces épisodes entrent dans les consciences, il faut une certaine fréquence dans les phénomènes et une durée à la catastrophe. Or la dernière inondation d'une certaine ampleur date de 1952. Depuis, plusieurs inondations ont eu lieu sans atteindre les niveaux historiques. Au final, rien ne remplace l'expérience vécu d'une inondation, même si la culture du risque tente de rafraichir les mémoires. 
À Toulouse, cette mémoire du risque s'exprime à travers la physionomie des paysages fluviaux garonnais, où les digues tiennent une place privilégiée. La chronologie et les motivations de l'endiguement toulousain présentent des similitudes mais aussi des différences avec ce que l'on peut observer ailleurs en France ou en Europe. Toulouse connaît aussi à la fin du siècle des Lumières une phase de construction de digues menée par les ingénieurs du roi, soucieux d'associer efficacité protectrice et esthétique urbaine. Par contre, nulle trace des grands travaux d'endiguement qui ailleurs sous le Second Empire deviennent un instrument de " gouvernement du territoire » (Guerrin, Bouleau, 2014). Ce n'est en fait qu'au moment où l'efficacité des digues et leur « rentabilité » commencent à être remises en cause que débute le grand endiguement toulousain (années 1960-1970). Les rénovations récentes (depuis 2010) actent par contre le nouveau statut de la digue en Europe : source potentielle de danger, elle doit faire l'objet d'examens fréquents, être rénovée, consolidée le cas échéant. Enfin, du point de vue de l'aménagement du territoire, elle est dorénavant considérée comme transparente et ne peut donc plus justifier un urbanisme qui ferait fi du risque dans les espaces qu'elle est censée protéger ${ }^{8}$.

8 Le PPRI de Toulouse, approuvé en décembre 2011, prend ainsi en compte un aléa " rupture de digue » qui conditionne les possibilités d'aménagement à l'arrière des digues concernées (http://www.toulouse-inondation. org/page-400/prevenir.html).

\section{Bibliographie}

Antoine J.-M., « Toulouse au temps des aygats », Patrimoine Midi-Pyrénées, nº 8, 2006, p. 67-73.

Antoine J.-M., Desailly B., « Villes et inondations dans le sud-ouest de la France de l'époque moderne au milieu du Xx ${ }^{e}$ siècle », dans Scarwell H.-J., Schmitt G., SAlvador P.-G. (dir.), Urbanisme et inondation : outils de réconciliation et de valorisation, Presses universitaires du Septentrion, Lille, 2013.

Arrouy J.-M., L'Île de Tounis, histoire d'un quartier au cœur de Toulouse (du XVII au XXe siècle), Loubatières, Toulouse, 2005.

BERTRAND G., « Le paysage entre la nature et la société », Revue géographique des Pyrénées et du Sud-Ouest, t. 49,1978 , p. 239-258.

Christophoul F., Carte géologique des terrasses alluviales de Garonne, France, 2013.

CUIET (centre urbain d'initiation à l'environnement de Toulouse), La Vie au bord du fleuve, 1993.

Chalande J., « Les inondations et les formations alluviales dans le bassin de la Garonne à Toulouse depuis le $\mathrm{XII}^{\mathrm{e}}$ siècle », Mémoires de l'Académie des sciences, inscriptions et Belles Lettres de Toulouse, t. XII, 1912.

Communauté urbaine du Grand Toulouse (CUGT), Grand parc Garonne. Plan guide à horizon 2030, 2012.

Devic C., VAIssÈte J., Histoire générale du Languedoc, t. X, Paya, Toulouse, 1746.

Direction déPARTEMENTALE DES TERRITOIRES DE LA Haute-Garonne, Notice de présentation du PPRI de Toulouse, 2011.
L’Europe, Convention européenne du paysage, série des traités européens, nº 176, 2000.

Fortuné M., Usages passés et écologie de la Garonne, thèse de doctorat en écologie, université PaulSabatier, Toulouse 1988.

Galabert F., Dépouillement des archives de la ville de Toulouse à propos des inondations de la Garonne, Archives de la ville de Toulouse, 1918.

Guerrin J., Bouleau G., « Remparts ou menaces ? Trajectoires politiques de l'endiguement en France, aux Pays-Bas et aux États-Unis », Revue internationale de politique comparée, vol. XXI, n 1,2014 , p. 89-109.

Hubschman J., « Les terrasses récentes de la Garonne et leur évolution », Bulletin de l'Association française pour l'étude du Quaternaire, 1975, $\mathrm{n}^{\text {os }} 3-4$, p. 137-147.

Lafaille (de) G., Annales de la ville de Toulouse, t. I et II, Toulouse-Coulomyes, 1687-1701.

LAfFont J.-L., Policer la ville. Toulouse, capitale provinciale au Siècle des lumières, thèse de doctorat en histoire, université de Toulouse le Mirail, 1997.

Lorillard M., Végétation, éboulements et glissements, t. I et II, thèse de doctorat de biogéographie, université Paul-Sabatier, Toulouse, 1970.

Marconis R., « Toulouse », dans Pinol J.-L. (dir.), Atlas historique des villes de France, Hachette, Paris, 1996.

Noé-Dufour A., Les Quartiers de Toulouse. L'île du Ramier, Accord, coll. «Itinéraires du patrimoine », 1998. 
Papillault R., Chapel E., PÉRÉ A., Toulouse territoires Garonne. Habiter en bord du fleuve, Presses universitaires du Mirail, Toulouse, 2012.

Piel C., " Hydrologie et projets urbains », dans Terrin J.-J., Villes inondables. Prévention, adaptation, résilience, Parenthèses, 2014.

Piquemil F., Les Politiques d'endiguement et leurs conséquences sur les paysages fluviaux dans la commune de Toulouse, mémoire de maîtrise de Géographie, université de Toulouse le Mirail, 2001.

Serret J., Les Débordements de la Garonne et ses affluents depuis les temps anciens jusqu'à nos jours, Imprimerie et Lithographie agenaises, Agen, 1900.

SYNDicAT MIXTE D'ÉTUdE ET DE PROGRAMMATION POUR L'AMÉNAGEMENT DE LA GARONNE (SMEPAG), Schéma de protection contre les eaux de Garonne, t. I, Monographies des crues de la Garonne (du pont du Roy au bec d'Ambès), 1989.

TAILlefer M., " L’Ancien Régime (XVI ${ }^{\mathrm{e}}$-XvIII ${ }^{\mathrm{e}}$ siècle), les prémices des grandes mutations », dans Bordes F. (dir.), Toulouse parcelles de mémoire, 2000 ans d'histoire urbaine au regard de huit siècles d'archives municipales, 2005.

Valette Ph., Carozza J.-M., Salles D., David M., Simonet G., « Construction géohistorique du sauvage de la Garonne toulousaine : quelle part de la naturalité dans les paysages fluviaux? ", Développement durable et Territoires, vol. V, $\mathrm{n}^{\circ} 3,2014$.

VALETTE Ph., « La Garonne à Toulouse, du centre ancien aux communes périurbaines : observation des paysages, évolution et intentionnalités », Norois, $\mathrm{n}^{\circ} 237,2015$.

Valette Ph., Girou A., Carozza J.-M., Desailly B., « Des balcons sur la Garonne ? Évolution des paysages fluviaux périurbains aux portes nord de Toulouse », Comprendre les paysages urbains, 135 e congrès du CTHS, Neuchâtel, 2013.

VAlEtTE Ph., CARozza J.-M., « Toulouse face à la Garonne : emprise de l'urbanisation dans la plaine inondable et géohistoire des aménagements fluviaux », Geographicalia, nos 63-64, 2013, p. 207-233. 